\title{
Title: Accuracy of wind farm visualisations: the effect of focal length on perceived accuracy
}

\begin{abstract}
Wind energy has been the fastest growing renewable energy technology for more than a decade. However, the visual impacts of wind farms are still one of the most controversial effects of wind energy development. Photomontage visualisations are frequently used in Visual Impact Assessments $^{1}$ (VIA) to give a sense of scale of the proposed development. Yet visualisations in VIAs are often perceived to underestimate the scale and magnitude of the visual impact of wind turbines. The aim of this multiphase mixed methods study is to explore the perceived accuracy of images that represent the visual impacts of both onshore and offshore wind farms. Field visits and data from a public survey are used to assess the accuracy of visualisations and to examine the effect of camera lens focal length on perception of scale of wind turbines. Results show that panoramic photomontages are perceived as the least accurate, while images taken at $75 \mathrm{~mm}$ focal length in full frame format are perceived as the most accurate form of representation of the scale and visual impact of wind turbines. These findings imply that the panoramic visualisation technique, which has been used for decades to predict the scale of wind turbines in VIAs, is ineffective in predicting accurately the visual impact of wind farms, and an alternative predictive technique is needed. For wind farm visualisations the use of $75 \mathrm{~mm}$ full frame image format is recommended in order to improve the accuracy, enable better informed decision making and avoid the loss of credibility of visualisations and VIAs.
\end{abstract}

Keywords: Visual Impact Assessment; wind farm; visualisations; panoramic photomontages, focal length

\footnotetext{
${ }^{1}$ List of abbreviations used in this article: VIA - Visual Impact Assessment
} 


\section{Introduction}

National Governments responsible for providing affordable and secure energy supplies to meet the growing energy demands of their populations are increasingly also tasked with addressing climate change in their energy policies (Bradshaw, 2010). The energy sector is the single biggest source of $\mathrm{CO}_{2}$ emissions (Baumert et al., 2005) and hence the transformation of the energy sector is required to reduce fossil fuel dependence and diversify the energy mix by increasing the share of renewable energy sources (World Energy Council, 2015). The United Kingdom (UK) under the 2009 Renewable Energy Directive (EU Directive 2009/28/EC) has a target to obtain $15 \%$ of its total energy and 30\% of electricity from renewable sources by 2020 . Although unlikely to meet the energy target (Energy and Climate Change Committee, 2016), progress on the electricity target has been good with $29.4 \%$ of UK electricity generated by renewables in 2017.

The UK has some of the best and most geographically diverse onshore wind resources, and has the largest available offshore area $\left(114000 \mathrm{~km}^{2}\right)$ in Europe for wind energy generation. Although current technology limits restrict offshore wind farm development to shallow waters (depths up to 25-30 metres), the UK still has the largest area, more than $60000 \mathrm{~km}^{2}$, suitable for offshore wind farm development (EEA, 2009). Wind energy thus has been the fastest growing renewable energy technology in the UK over the last decade (MacLeay et al., 2015). Wind is the single biggest source of renewable electricity generation in the UK, making up $50 \%$ of the total renewable electricity generation in 2017 compared with bioenergy $(32 \%)$, hydro (6\%) and solar photovoltaic (12\%) (DBEIS, 2018). Offshore wind reached $21 \%$ and onshore $29 \%$ of renewable electricity sources in 2017 (DBEIS, 2018).

Before the development of wind energy projects can proceed, to meet the legal requirement for Environmental Impact Assessment (EIA), a range of environmental impacts including noise, ecological impact on wildlife and birds, electromagnetic interference, and landscape and visual impacts have to be considered (Dai et al., 2015). Landscape and visual impacts are often the most significant and tend to be the most controversial effects of wind farm development (Molnarova et al., 2012). A Visual Impact Assessment (VIA) is therefore carried out as part of an EIA to assess and predict the magnitude of visual impacts of the proposed development.

Basic physical attributes such as landscape attributes, height and colour of wind turbines, distance between the wind farm and the viewer, weather and lighting conditions all affect the visual impact of wind turbines (Bishop and Miller 2007). In the academic literature several methods exist that predict the visual impact of wind farms based on these parameters (e.g. Hurtado et al., 2004; Torres Sibille et al., 2009; Rodrigues et al., 2010). In practice however, the two complimentary techniques of Zone of Theoretical Visibility (ZTV), which involves a calculation of the areas from which wind turbines may be visible, and visualisations are used to predict visual impacts (LI and IEMA, 2013).

This paper focuses on two-dimensional computer generated photomontage visualisations (hereafter referred to as 'visualisations'), which are most commonly used for wind farm VIAs (LI and IEMA, 2013). Visualisations recently have become subject to criticism for showing patterns of inconsistencies in the representation of content elements and their locations (e.g. 
Corry, 2011; Downes and Lange, 2015). Issues with the perceived accuracy of the size and visual impact of wind turbines have also been highlighted by some studies (University of Newcastle, 2002; Macdonald, 2007; Macdonald, 2012).

The aim of this paper is to assess the accuracy of wind farm visualisations and learn how well the technique of panoramic photomontage visualisation performs in predicting accurately the visual impacts of both onshore and offshore wind farms. 'Accuracy' in this paper is defined as follows: "The similarity in appearance between the simulated scene and the real scene after the project has been built" (Sheppard, 1989, p. 203). Ex-ante visualisations produced for VIAs of one onshore and one offshore wind farm in North Norfolk, England are compared with a sample of 134 viewers' direct observations of the wind farms post-construction. This study also aims to assess the effect of focal length on the perception of scale of wind turbines in images as a person's perception of distance and scale can be influenced depending on the focal length used.

The following set of research questions were posed to guide the study: a) Do panoramic visualisations presented in VIAs provide an accurate prediction of the visual impacts of wind farms? Is the experienced visual impact of wind farms as predicted in the VIA? If not, why? b) Does the public feel that wind farm visualisations accurately represent the visual impacts they experience when viewing wind farms post-development? If not, is it possible to identify a consensus on a form of representation that they feel is most accurate? c) What recommendations can be made to improve the accuracy of wind farm visualisations?

The remainder of this paper is organised as follows. Section 2 will describe the study area and outline the methodology used to collect and analyse data. Section 3 will discuss some theoretical underpinnings of the research. Section 4 will present the results of the analysis while Section 5 will discuss the key themes that emerged from the analysis. Lastly, Section 6 will conclude and give recommendations on how the accuracy of wind farm visualisations might be improved.

\section{Materials and methods}

\subsection{Study Area}

This paper uses a case study of an onshore and offshore wind farm in North Norfolk, England (see Figure 1 and Table 1). The offshore wind farm, with its 88 turbines located off the coast of North Norfolk, is the third largest fully operational offshore wind farm in Norfolk with a capacity of 316.8 MW, and the ninth largest in the UK (RenewableUK, 2018). The onshore wind farm, located in North West Norfolk, consists of six wind turbines with a total installed capacity of $15 \mathrm{MW}$. Although it is the largest wind farm on land in Norfolk in terms of total capacity, it is considered as a medium sized development when compared to other onshore wind farms at the national level (RenewableUK, 2018).

The case studies were selected because they were the only wind farms in the study area that (1) consist of large wind turbines (minimum 2.0 MW capacity with 60-100 m tower height and 
min. $40 \mathrm{~m}$ blades) and thus have greater visual impact than smaller wind turbines (Bishop and Miller, 2007), (2) were fully operational at the time of the research, and (3) had accessible high resolution photomontage visualisations.

Table 1. Summary of the main characteristics of the two wind farms

\begin{tabular}{lrr}
\hline & Offshore wind farm & Onshore wind farm \\
\hline Location & Off the North Norfolk Coast & North West Norfolk \\
\multicolumn{1}{c}{ Latitude } & $53^{\circ} 8^{\prime} 5.9^{\prime \prime}$ & $52^{\circ} 52^{\prime} 46.4^{\prime \prime}$ \\
$\quad 1^{\circ} 8^{\prime} 49.2^{\prime \prime}$ & $0^{\circ} 43^{\prime} 414^{\prime \prime}$ \\
Longitude & $17-23 \mathrm{~km}$ off the North & 4 km south the AONB \\
AONB & 2006 & 2010 \\
Year EIS was produced & 2011 & 2015 \\
Operation started & 88 & $60 \mathrm{~m}$ \\
Number of turbines & $80 \mathrm{~m}$ & $45 \mathrm{~m}$ \\
Turbine tower height (metres) & $52 \mathrm{~m}$ & $125 \mathrm{~m}$ \\
Blade length (metres) & $132 \mathrm{~m}$ & $2.5 \mathrm{MW}$ \\
Height to blade tip (metres) & $3.6 \mathrm{MW}$ & $15 \mathrm{MW}$ \\
Individual turbine capacity & $316.8 \mathrm{MW}$ & \\
Total installed capacity & Approx. 220,000 homes & Approx. 10,600 homes \\
Number of homes supplied & & \\
(annually) & &
\end{tabular}

Since 1968, approximately $453 \mathrm{~km}^{2}$ of the Norfolk coast has been designated as an Area of Outstanding Natural Beauty (AONB) under the National Parks and Access to the Countryside Act 1949, in recognition of its national and international landscape importance. Although the wind farms are located outside the boundary of the Norfolk Coast AONB, they are both visible from within it (Figure 1). The accuracy of visualisations depicting wind farms sited in/near designated landscape areas is especially important as visualisations are used at the planning stage to determine whether a development has significant visual impacts on the sensitive landscape. 


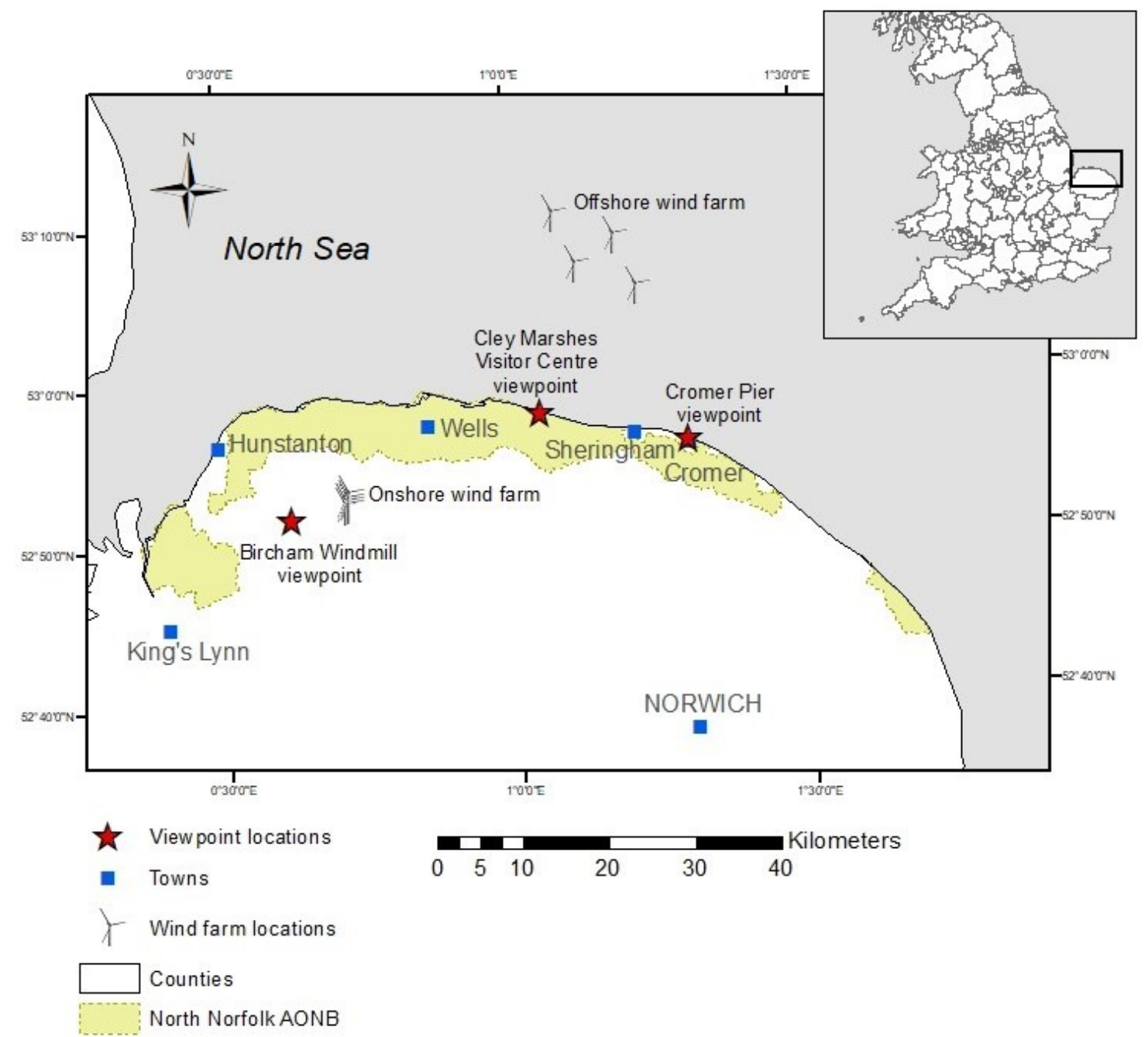

Figure 1. Map showing the study area in North Norfolk, the North Norfolk AONB, the location of the onshore and offshore wind farms and the three viewpoints used for the public survey (note: turbine symbols represent the location of the wind farms, not all turbines are shown).

\subsection{Data}

Data used in this research were collected in three phases between July and September 2015 and consist of three types: key informant interviews, field visits combined with document analysis and a public survey. Ethical approval for this study was granted by the University of East Anglia International Development Research Ethics Committee.

\subsubsection{Key informant interviews}

Five exploratory key informant interviews were conducted to investigate the perceptions around the representation of visual impacts of wind farms and the accuracy of panoramic photomontage visualisations. Participants included two local government officers working in planning, two local residents living nearby either the onshore or the offshore wind farm and an 
informant from a local non-profit public authority. Interview questions were structured into three categories (1) perceptions of wind energy, (2) perceptions of the visual impacts of wind turbines, and (3) views about documents and visualisations produced in the planning phase of the wind farms. Open coding of qualitative interview data was used to generate concepts with the coding categories empirically grounded in the informants' responses, following a grounded theory approach (Glaser and Strauss, 1967).

\subsubsection{Field visits}

Photomontage visualisations and information on viewpoints were extracted from VIAs and written text on predicted visual impacts was analysed prior to field visits. Field visits were made to 11 viewpoints for which photomontage visualisations were available. At each viewpoint the first author compared visualisations with post-development conditions and assessed the accuracy of photomontages based on the following criteria: number of turbines visible, location and size of wind turbines (Corry, 2011). The 'number of turbines visible' criterion was not used for assessing the accuracy of offshore wind farm visualisations as no visualisations were produced that depicted the post-development layout option with the correct number of turbines. As specified in the published EIA, all panoramic photomontages were printed at A3 size and were viewed from the recommended viewing distances.

After the assessment of the accuracy of the photomontages, eight full frame photographs were taken of the wind farms post-construction by the first author at focal lengths of 50, 60, 70, 75, $80,90,100$ and 110mm (Hunter and Livingstone, 2012). However, only three of these images $(50,75$ and $90 \mathrm{~mm}$ ) were used in the public survey as the pilot survey showed that pilot participants had difficulties with distinguishing between the eight images.

Images were taken with a crop frame digital single-lens reflex camera (DSLR), as the authors had no access to a full frame camera at the time of the research. Therefore, in order to obtain the same field of view as the full frame sensor the focal lengths were divided by the DSLR's crop factor $(2.0 \mathrm{x})$.

\subsubsection{Public survey}

A public survey was conducted to validate the findings of the field visits and to examine the effect of different focal lengths on perception of scale and distance amongst a sample of 134 viewers. The survey was undertaken at three viewpoints (see Figure 1), which were selected based on their accessibility and the number of passers-by. At each viewpoint, participants were asked to compare a set of four images which consisted of the panoramic photomontage from the VIA, and three of the authors photographs at focal lengths of $50 \mathrm{~mm}, 75 \mathrm{~mm}$ and the $90 \mathrm{~mm}$ (see Figure 2).

Structured face-to-face interview questions were used to evaluate the perceived accuracy of the four different images at each viewpoint. Images were given in random order and respondents were not told which images were the developer's photomontages and which the author's photographs in order to avoid bias in the results. Respondents were asked to compare the wind farm in the images with the wind farm in reality and pick out any differences (e.g. size, distance, 
number, colour of turbines). They were asked to indicate whether the size of turbines in each image was underestimated, about right or overestimated. Lastly respondents placed the images in rank order based on how accurately they perceived the wind farm was depicted in each of the images when compared to reality. Basic information on age, gender and level of concern about the visual impact of wind turbines was also collected. The population characteristics of the respondents are summarised in Table 2.

Quantitative analysis of the public survey data was performed in SPSS. The chi-square goodness-of-fit test was performed to determine whether the distribution of respondents who perceived that the size of the wind turbines was underestimated, about right, or overestimated were equal for each image. By chance alone, an equal distribution of the three categories (under-, overestimated, neither) would be expected. Statistically significant chi-square results were further analysed by calculating standardised residuals in order to determine which cells contributed the most to the significant chi-square values (Sharpe, 2015). Differences in perceived accuracy based on the rank-ordering of the four images taken at different focal lengths were analysed by the Friedman test. Separate Wilcoxon signed-rank tests on the different combinations of image types were run to examine where the differences actually occurred. Since multiple comparisons were made when performing the Wilcoxon singed-rank test, the Bonferroni adjustment was applied (Bender and Lange, 2001).

Table 2. Public survey sample characteristics

\begin{tabular}{llrrr}
\hline & & \multicolumn{3}{c}{ Number of respondents } \\
\cline { 3 - 5 } Variables & Categories & Cromer & Cley & Bircham \\
\hline Gender & Male & 18 & 32 & 15 \\
Age & Female & 27 & 23 & 19 \\
& $18-24$ & 10 & 4 & 5 \\
& $24-34$ & 8 & 2 & 5 \\
& $35-44$ & 4 & 8 & 2 \\
& $45-54$ & 8 & 10 & 7 \\
& $55-64$ & 8 & 13 & 5 \\
Concern about visual & Concerned & 6 & 11 & 7 \\
impact of wind turbines & Not concerned & 1 & 7 & 3 \\
& Neither & 13 & 21 & 14 \\
Total & & 8 & 18 & 12 \\
& & $\mathbf{4 5}$ & $\mathbf{5 5}$ & $\mathbf{3 4}$ \\
\hline
\end{tabular}




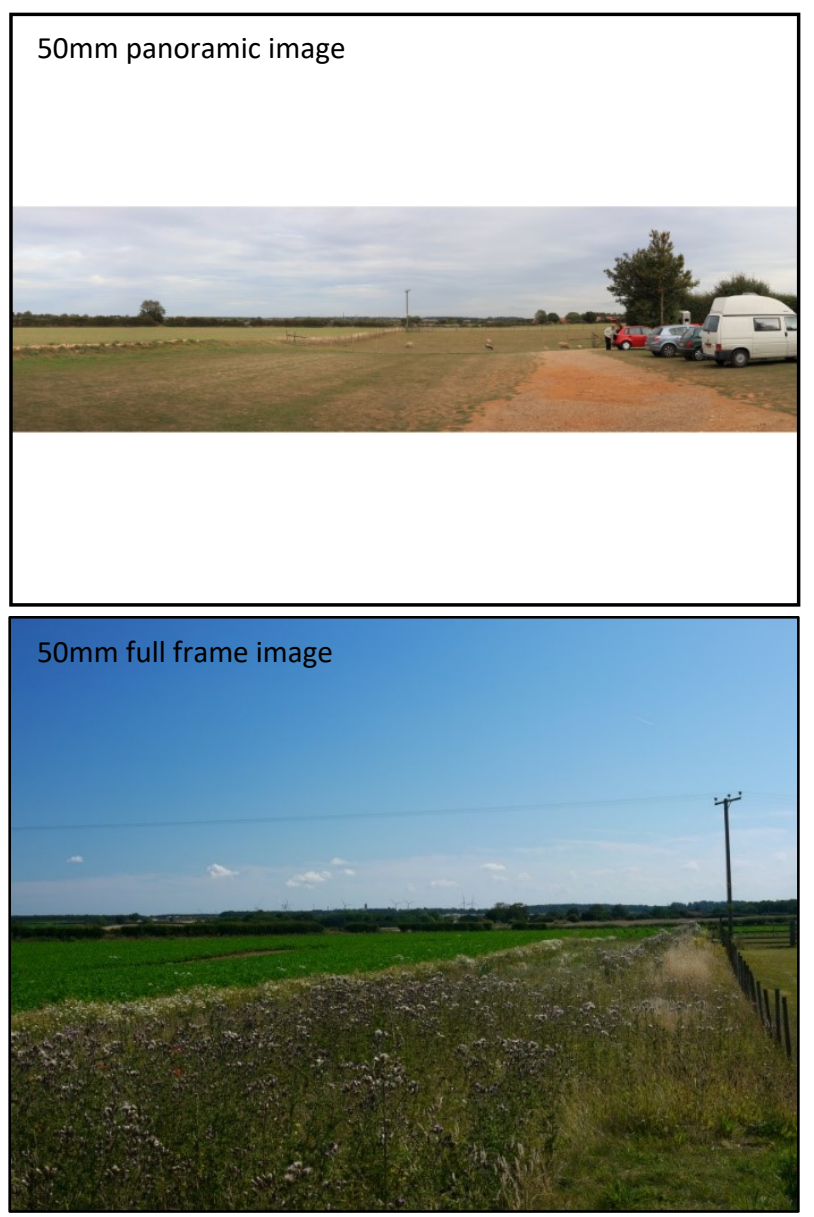

Figure 2 Four representations of the onshore wind farm from the Bircham viewpoint (printed at A3 size for use in public survey)
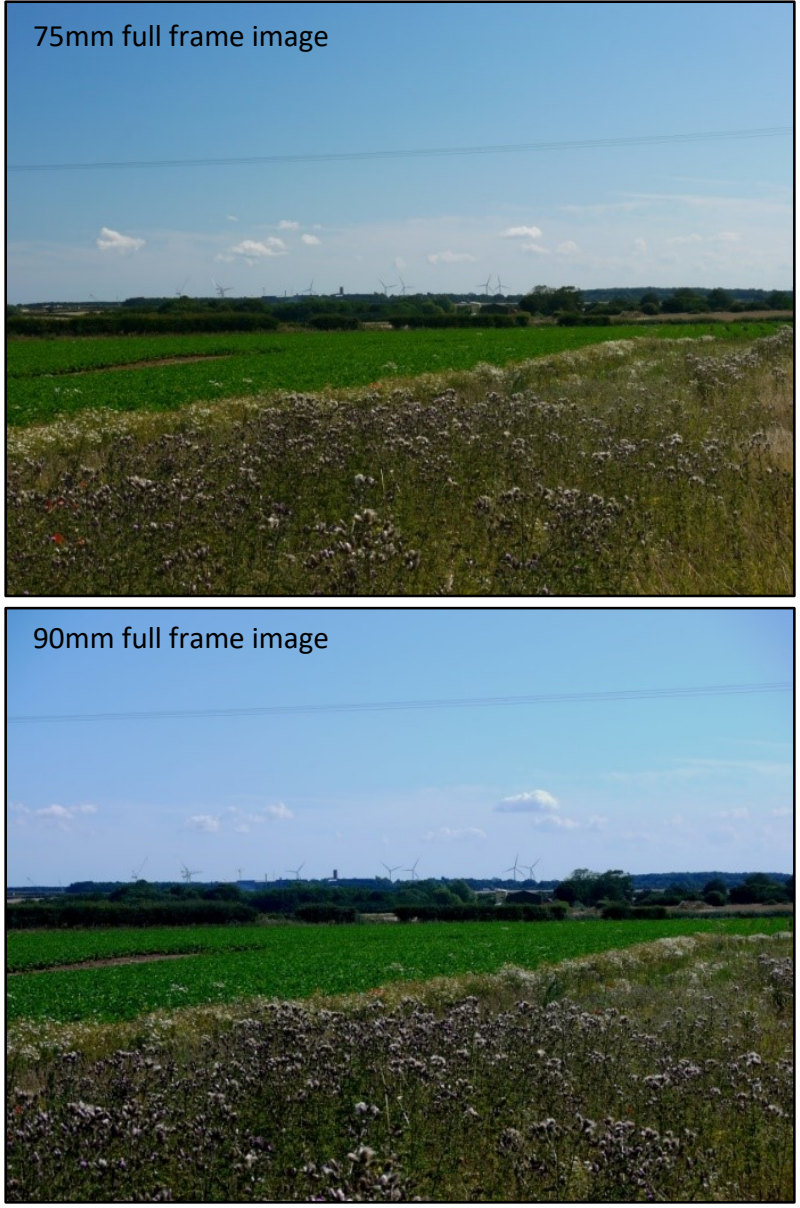


\section{The accuracy of visualisations for visual impact assessment}

The term visualisation in the broad sense can refer to both traditional forms of representations (e.g. artistic impressions, hand drawings and perspectives) as well as computer generated representations (e.g. photo- and videomontages and three-dimensional models) (Pietsch, 2000; Bates-Brkljac, 2008). Visualisations are regarded as powerful communication tools as they are capable of conveying and clarifying complex information, and they are easily understood by both non-professionals and the general public (Pietsch, 2000). The quality of visualisations plays an important role in determining the outcome of planning applications where visual impacts are significant (Downes and Lange, 2015).

The level of realism/abstraction and accuracy provided by visualisations has important implications for validity (Oh, 1994; Watzek and Ellsworth, 1994; Daniel and Meitner, 2001; Lange, 2001). Wind farm visualisations tend to have low levels of abstraction and a high degree of realism due to the use of computer modelling to superimpose the proposed turbines on to a photographic background. However, visualisations that look highly realistic may represent the proposed development inaccurately, due to for example unrealistic camera angles and inaccurate depiction of the scale of the turbines (Downes and Lange, 2015). It is widely agreed that visualisations should predict the nature and extent of landscape change as accurately as possible (Smardon and Karp, 1993; Sheppard, 1989). An accurate visualisation should 'show a view of the development that is not significantly different in appearance from the real view when seen from the same viewpoint' (Sheppard, 1989, p. 76).

The accuracy of visualisations is limited by their inability to convey movement and sound or communicate information on the attributes of objects such as materials, surface texture and age (Wergles and Muhar, 2009). When visually experiencing a scene, we are capable of perceiving distance, depth, scale and speed by using numerous visual cues (Gibson, 1950). On the contrary, when viewing 2D images it becomes difficult to assess distance and scale of distant objects in photographs. In addition, the lack of distinct and recognisable scaling features for wind turbines also make it difficult to determine the height of turbines in visualisations (Macdonald, 2012).

Perceived scale accuracy can vary from person to person and by project type (Watzek and Ellsworth, 1994). Moreover, different focal lengths of camera lenses can have different effects on our perception of distance and scale of objects in images, therefore careful choice of focal length becomes crucial for providing an accurate sense of scale when producing visualisations. In general, the shorter the focal length of the lens, the greater the perceived distance and the smaller the scale of distant objects in photographs (Kraft et al., 1986). A lens with a focal length of $50 \mathrm{~mm}$ on a full frame camera is often referred to as 'standard' or 'normal' lens because it represents the field of view of the human eye quite accurately. The use of the $50 \mathrm{~mm}$ focal length therefore has been the industry standard for the production of wind farm visualisations. However, best practice has been to produce wind farm visualisations in panoramic format, where a series of full frame images are stitched together to create a seamless image with a wide angle view of the landscape (LI and IEMA, 2013; SNH, 2017). Consequently, panoramas need to be viewed from specific viewing distances so that the individual photographs that make up 
the panoramas are viewed in the correct perspective and give an accurate representation of the visual impact of the proposed development.

Monitoring the actual impacts of a development post-construction and evaluating the effectiveness of the predictive techniques used in VIAs can help ensure the credibility of EIA (Bisset, 1984, Wessels, 2013). However, research that evaluates the actual performance of predictive techniques used in VIAs is limited (Wood, 2000; Churchward et al., 2013). A few studies exist that assess the validity and accuracy of landscape and architectural visualisations (e.g. Bishop and Rohrmann, 2003, Corry, 2011; Downes and Lange, 2015). However, with the exception of Bishop and Rohrmann (2003), these studies compare ex-ante visualisations with ex-post photographs of finished sites, and none undertakes a comparison between visualisations and the experience of respondents viewing the same sites directly, as is done in this study.

\section{Results}

\subsection{Key informant interviews}

Key informant interviews gave a back-drop for understanding the nature of potential issues with photomontage visualisations and the methodology used in VIAs to predict the visual impacts of proposed wind farms. None of the key informants had the opportunity to compare visualisations with real life situations, therefore their responses were grounded on their experience of visual impacts rather than on empirical observations.

Key informants expressed contrasting opinions on the accuracy of visualisations and the quality of VIAs. Discrepancies in experiences and diverse opinions on the accuracy of visualisations contributed to new insights that were pursued further in the field visits and public survey. Interviews with local government informants revealed that visualisations were generally believed to be fairly accurate. "In terms of making an informed choice, as a potential objector, I never really had an issue with the ones I have seen. Generally, in my experience the representations I have seen are pretty accurate" (informant from local government). Nevertheless, informants highlighted that the quality of visualisations can vary widely. "Some of them are fairly good representations of how they [wind turbines] might look. Having said that, in one or two instances they [photographs] were taken from vantage points where perhaps the turbine wouldn't be seen. For example, in a couple of instances the turbines were placed behind trees. If you stepped away, say 10-15 metres one way or another, the turbines would have been visible. We also had instances where the photographs were of poor quality. But generally I think the scale and interpretation are pretty good" (planning officer, local government).

In addition to mentioning the varying quality of visualisations, it is worth noting the planning officer's comments on vantage points. Field visits to viewpoints also revealed that although visualisations represented the location of turbines fairly accurately, the majority of the photographs were taken from locations where one or more turbines were screened by foreground vegetation (see Figure 3 as an example). Although positioning the camera free from 
foreground screening at any viewpoint is vital for the production of accurate visualisations, this issue will not be further discussed here due to the scope of the paper.

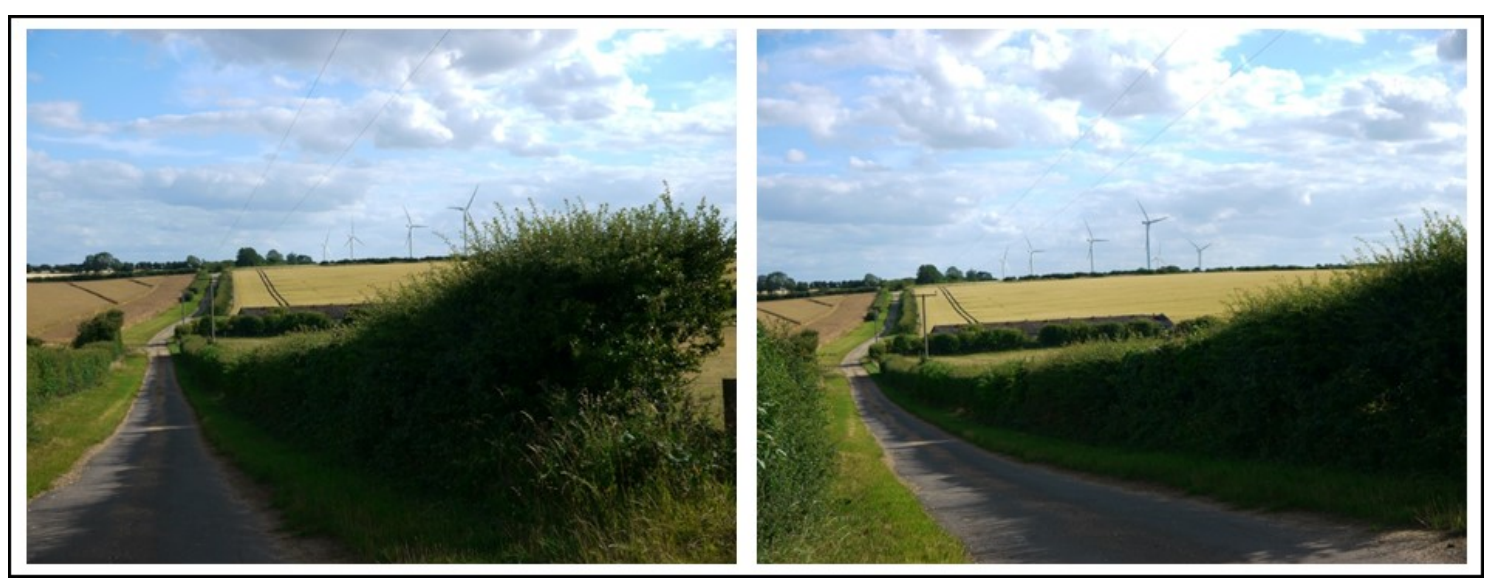

Figure 3. When taking a photograph from the original viewpoint used in the VIA, two wind turbines are screened by the vegetation in the foreground and only four turbines are visible (left image). All six turbines become fully visible when taking the photograph from the other side of the road, which is approximately three metres from the original viewpoint (right image).

Contrary to the perceptions of the local government informants, the informant from a nonprofit public authority and one of the local residents expressed concerns over the quality and accuracy of visualisations. Both informants felt that visualisations often underestimate the visual impact of turbines. "They all produce visualisations in some form to show what they [wind turbines] are going to look like. But what you find when they go up is that they are far more visible than you thought they were going to be" (Public authority informant). "I tried taking photographs of them [offshore wind turbines]. I have got a quite primitive digital camera, but to get anything like how I feel I see, I have to magnify the image quite a lot" (local resident). The later informant highlights the issue of focal length and how this can influence the perception of size of wind turbines in photographs, which will be discussed in detail in section 4.3.

\subsection{Field visit}

This section reports the first author's perception of the accuracy of the panoramic photomontages at each viewpoint. Field visits revealed that the panoramic photomontages depicted the size of both onshore and offshore wind turbines inaccurately when compared with the constructed reality. At eight out of the eleven viewpoints, the size of turbines was underestimated and looked smaller in photomontages than in reality, even though the panoramic photomontages were viewed from the recommended viewing distances as specified in the VIAs. At the remaining three viewpoints, the wind turbines were screened by landscape features such as vegetation in the photomontages therefore it was not possible to assess the size of wind turbines in photomontages and compare it with post-development conditions. 


\subsection{Public survey}

The purpose of the public survey was to validate the findings of the field visit and to assess the accuracy of visualisations and the effect of different camera lens focal length on perception of scale and distance of wind turbines.

\subsubsection{Size of wind turbines}

The percentage of responses indicating whether the size of wind turbines was underestimated, overestimated or depicted about right in each image are summarised in Figure 4. The results of the chi-square goodness-of-fit test revealed that the proportion of responses across the categories 'underestimated', 'overestimated' and 'about right' were significantly different from their expected frequencies for the $50 \mathrm{~mm}$ image $(\chi 2(2)=161.911, \mathrm{p}<0.001)$, the $75 \mathrm{~mm}$ image $(\chi 2(2)=18.978, \mathrm{p}<0.001)$ and the $90 \mathrm{~mm}$ image $(\chi 2(2)=63.511, \mathrm{p}<0.001)$. No chi-square goodness-of-fit test was performed for the panoramic photomontage as all the respondents $(\mathrm{N}=134)$ indicated that the panoramic photomontages underestimated the size of both on- and offshore wind turbines when compared to reality.

Calculation of standardised residuals (Sharpe, 2015) revealed that there was always a preferred category for the 50,75 and 90mm image which was selected more often than would be expected by chance. The observed frequency of the category 'underestimated' was significantly above its expected frequency for the $50 \mathrm{~mm}$ image $(\mathrm{N}=114)$, while the categories of 'about right' $(\mathrm{N}=19)$ and 'overestimated' $(\mathrm{N}=2)$ were significantly below their expected frequency, indicating that significantly more respondents perceived that the $50 \mathrm{~mm}$ image underestimated the size of on- and offshore wind turbines than would be expected by chance alone.

The observed frequency of the category 'about right' was significantly above its expected frequency for the $75 \mathrm{~mm}$ image $(\mathrm{N}=67)$, indicating that significantly more respondents thought the $75 \mathrm{~mm}$ image depicted the size of on-and offshore wind turbines correctly than would be expected by chance. The observed frequencies of the categories 'overestimated' $(\mathrm{N}=73)$ and 'about right' $(\mathrm{N}=60)$ were significantly above their expected frequencies for the $90 \mathrm{~mm}$ image, while the observed frequency of 'underestimated' was significantly below its expected frequency $(\mathrm{N}=2)$.

Separate inspection of standardised residuals of the onshore and offshore images revealed that for the onshore wind farm, the category 'overestimated' was significantly above its expected frequency for the $90 \mathrm{~mm}$ image, which indicates that significantly more respondents believed that the $90 \mathrm{~mm}$ focal length overestimated the size of onshore wind turbines than would be expected by chance. For the offshore images, there was a lack of consensus on whether the $90 \mathrm{~mm}$ focal length overestimated or depicted the size of turbines about right as both the categories 'about right' and 'overestimated' were significantly above their expected frequencies. 

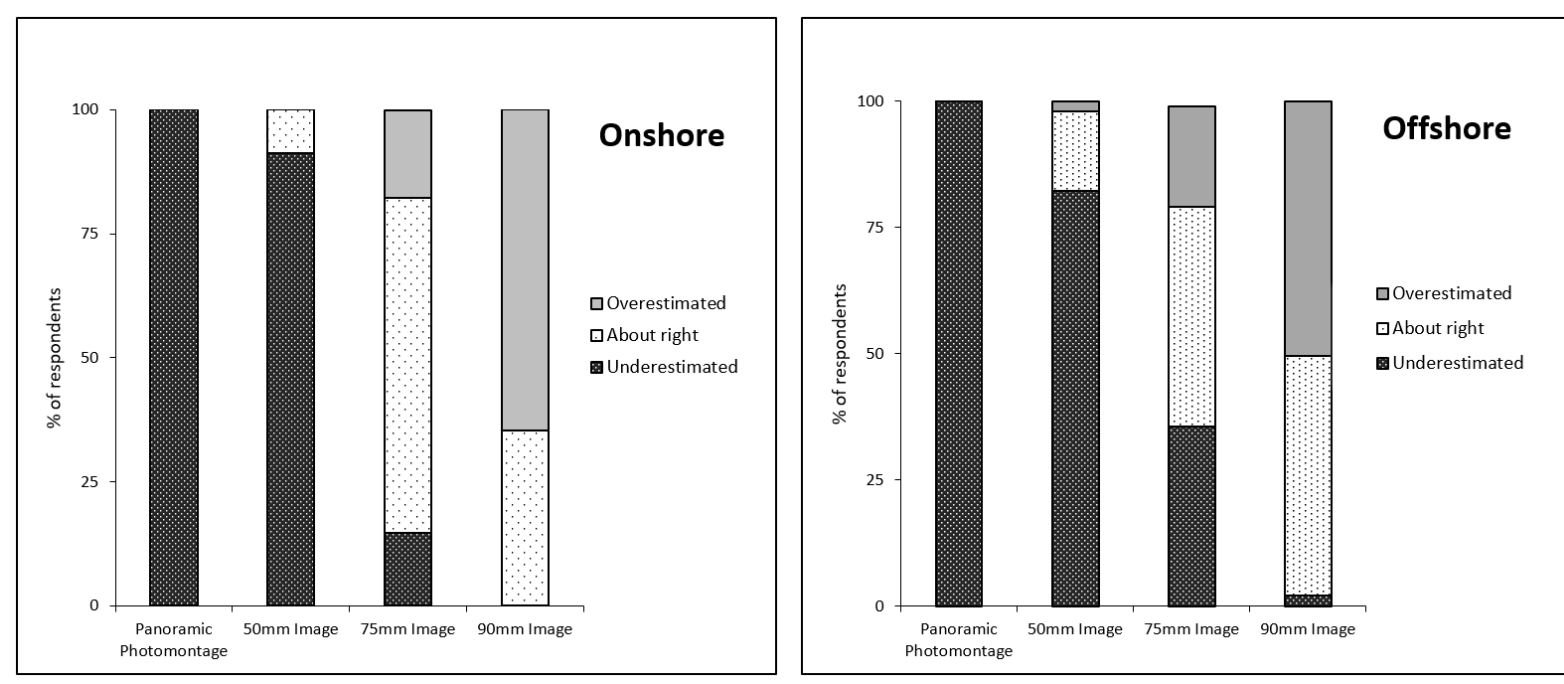

Figure 4. Percentage of respondents who thought the size of turbines was underestimated, overestimated or depicted about right in each image type.

\subsubsection{Overall perceived accuracy using rank order}

The Friedman test revealed a statistically significant difference in overall perceived accuracy among the four image types $\left(\chi^{2}(3)=199.478, p<0.001\right)$. According to the mean ranks the order of preference of the images from most accurate to least accurate was as follows: $75 \mathrm{~mm}$ image, $90 \mathrm{~mm}$ image, $50 \mathrm{~mm}$ image and the panoramic photomontage (see Table 3 for mean ranks).

Table 3. Mean ranks for each image type ordered from most accurate ( $75 \mathrm{~mm}$ image) to least accurate (panoramic photomontage). Rank 1 signifies most accurate, rank 4 signifies least accurate.

\begin{tabular}{lrrr}
\hline & $\begin{array}{r}\text { combined onshore } \\
\text { and offshore } \\
(\mathrm{n}=134)\end{array}$ & Onshore $(\mathrm{n}=34)$ & Offshore $(\mathrm{n}=100)$ \\
\hline $75 \mathrm{~mm}$ Image & 1.61 & 1.38 & 1.69 \\
$90 \mathrm{~mm}$ Image & 2.19 & 2.29 & 2.15 \\
$50 \mathrm{~mm}$ Image & 2.44 & 2.35 & 2.47 \\
Panoramic Photomontage & 3.76 & 3.97 & 3.69 \\
\hline
\end{tabular}

Post hoc analysis with the Wilcoxon signed-rank test with Bonferroni adjustment revealed that the observed differences in perceived accuracy among the four image types were significant, with the exception of the comparison between the $90 \mathrm{~mm}$ and the $50 \mathrm{~mm}$ image (see Table 4 for test results). Since the post hoc test did not indicate a statistically significant difference between the mean ranks of the $90 \mathrm{~mm}$ and $50 \mathrm{~mm}$ images, it cannot be assumed that the $90 \mathrm{~mm}$ image was perceived as more accurate than the $50 \mathrm{~mm}$ image. Nevertheless, the Wilcoxon signed-rank 
test showed that the mean rank of the $75 \mathrm{~mm}$ image (1.61) was significantly closer to 1 (most accurate rank) than the mean ranks of the other three image types, indicating that the $75 \mathrm{~mm}$ full frame image was perceived as the most accurate form of representation of the visual impact of wind turbines.

On the contrary, respondents perceived the panoramic photomontages as the least accurate form of representation (mean rank 3.76). Of the total 134 respondents, 106 ranked the panoramic photomontage as the least accurate, while 24 ranked it as the second least accurate image of the four and none ranked it as the most accurate image. There were no significant gender or age differences in perceived accuracy of different types of visualisations. Furthermore, there were no differences between the ranks given by respondents who were concerned about the visual impact of wind farms and those who were not concerned. For all groups, the $75 \mathrm{~mm}$ image was perceived as the most accurate form of representation, while the panoramic photomontage was perceived as the least accurate, when considering the mean rank by group.

For both on- and offshore images, the Wilcoxon signed-rank test revealed statistically significant results. The $75 \mathrm{~mm}$ image (with the lowest mean rank of 1.38 for the onshore and 1.69 for the offshore, see Table 3) was perceived as the most accurate form of representation, while the panoramic photomontage (with the highest mean rank of 3.97 for onshore and 3.69 for offshore) was perceived as the least accurate form of representation. As was the case with the combined results, according to the Wilcoxon signed-rank test results the mean ranks of the $50 \mathrm{~mm}$ image and the $90 \mathrm{~mm}$ image were not significantly different for the onshore and offshore wind farms (Table 4).

Table 4. Results of the Friedman and Wilcoxon signed rank tests.

\begin{tabular}{|c|c|c|c|c|c|c|c|}
\hline & \multirow[t]{2}{*}{ Friedman test } & \multicolumn{6}{|c|}{ Wilcoxon signed-rank test $(Z)$ Image comparisons } \\
\hline & & $\begin{array}{l}75 \mathrm{~mm}- \\
50 \mathrm{~mm} \\
\text { image }\end{array}$ & $\begin{array}{l}90- \\
50 \mathrm{~mm} \\
\text { image }\end{array}$ & $\begin{array}{l}\text { Photo- } \\
\text { montage } \\
-50 \mathrm{~mm} \\
\text { image }\end{array}$ & $\begin{array}{l}90 \mathrm{~mm}- \\
75 \mathrm{~mm} \\
\text { image }\end{array}$ & $\begin{array}{l}\text { Photo- } \\
\text { montage - } \\
75 \mathrm{~mm} \\
\text { image }\end{array}$ & $\begin{array}{l}\text { Photo- } \\
\text { montage - } \\
90 \mathrm{~mm} \\
\text { image }\end{array}$ \\
\hline $\begin{array}{l}\text { Combined } \\
\text { onshore } \\
\text { and } \\
\text { offshore } \\
(\mathrm{n}=134)\end{array}$ & $\chi^{2}(3)=199.48 *$ & $Z=-7.28^{*}$ & $\begin{array}{l}Z=-1.55 \\
(p=.121)\end{array}$ & $Z=-9.39 *$ & $Z=-4.53^{*}$ & $Z=-10.17 *$ & $Z=-8.69^{*}$ \\
\hline $\begin{array}{l}\text { Onshore } \\
(n=100)\end{array}$ & $\chi^{2}(3)=70.91 *$ & $Z=-4.02 *$ & $\begin{array}{l}\mathrm{Z}=-.28 \\
(\mathrm{p}=.777)\end{array}$ & $\mathrm{Z}=-5.20^{*}$ & $Z=-3.81^{*}$ & $Z=-5.265^{*}$ & $Z=-5.03 *$ \\
\hline $\begin{array}{l}\text { Offshore } \\
(n=34)\end{array}$ & $\chi^{2}(3)=131.74 *$ & $Z=-6.08^{*}$ & $\begin{array}{l}\mathrm{Z}=-1.46 \\
(\mathrm{p}=.143)\end{array}$ & $Z=-7.81 *$ & $\mathrm{Z}=-3.08 * *$ & $Z=-8.745^{*}$ & $Z=-7.19 *$ \\
\hline
\end{tabular}




\subsubsection{Viewing distance}

As mentioned in Section 3, only panoramic photomontages are required to be viewed from specific viewing distances. However, none of the respondents viewed the panoramic photomontages from the recommended viewing distances, which were specified at the bottom of each image. Instead panoramas, as well as the full frame images, were viewed from a comfortable distance of arms-length. The information specifying the recommended viewing distance at the bottom of the panoramas were either not noticed by viewers $(97 \%)$ or was believed to be technical information irrelevant to the viewer $(3 \%)$. The perception of respondents did not change when the recommended viewing distance was enforced for the panoramic photomontage. The size of wind turbines was thought to be underestimated in the panoramic photomontages regardless of whether the viewing distance was enforced or not.

\section{Discussion}

The results for the two case study wind farms suggest that there is a need to improve the accuracy of photomontage visualisations produced at the planning stage. The results of this study are consistent with the findings of Corry (2011) and the University of Newcastle (2002) that visualisations are generally accurate in positioning the turbines, however, on the whole they underestimate the size of the turbines and thus suggest a much reduced visual impact than is experienced post-construction. In order to avoid the underestimation of the size of turbines, the University of Newcastle (2002) recommends the use of 50mm full frame images. However, according to the results of the public survey, the $50 \mathrm{~mm}$ full frame image format underestimated the visual impact of wind turbines both onshore and offshore for most respondents. The results of the rank-ordering of images based on overall perceived accuracy are in agreement with the findings of Macdonald (2012) and Hunter and Livingstone (2012) and suggest that $75 \mathrm{~mm}$ full frame format should be used for the production of wind farm visualisations in order to predict the scale of proposed wind farms more accurately.

Yet the latest guidance on wind farm visualisation still recommends the use of panoramic photomontages formed from several $50 \mathrm{~mm}$ photographs stitched together (SNH, 2017). Although visualisation guidance is being improved gradually, the dissemination of research findings into VIA practice has been rather slow. The SNH now accepts that the $75 \mathrm{~mm}$ full frame images should be used to understand the size of the development and its distance from the viewpoint, however the production of $75 \mathrm{~mm}$ full frame visualisations is still not a compulsory requirement of the VIA and EIA process. A recently published draft document on Photography and Photomontage in Landscape and Visual Impact Assessment by the Landscape Institute (2018) also suggests that images may be printed larger than 'mathematically correct' in order to give a better impression of scale, especially when taking visuals to site. However, these practices are merely suggestions rather than standards. 
It is widely acknowledged that the primary aim of visualisations is to give a reasonable representation of the scale of wind turbines so that the potential visual impact of the proposed development can be fully understood (SNH, 2017). Nevertheless, developers might prioritise a particular message (e.g. the proposed wind farm has minor visual impacts) for a specific future outcome (e.g. gaining planning permission), while the accuracy of visualisations might be of secondary importance. Although visual impacts are not the most influential reason for the refusal of planning applications, developments do get refused based on their visual impacts (van Rensburg et al., 2015). The fear of potential rejection of wind farms based on visual impacts, especially relevant to protected areas such as the Norfolk Coast AONB, and the tension between visual impacts and the need for the generation of clean energy to address climate change and secure a diverse energy supply have likely contributed to the slow dissemination of research findings into VIA practice.

The siting of new infrastructure such as wind turbines unavoidably creates visual impacts. Nevertheless, the impacts should be predicted as accurately as possible and the performance of predictive techniques for visual impacts should be constantly evaluated in order to avoid the transferring of ineffective predictive methodologies (Tomlinson and Atkinson, 1987). With accurate impact prediction, mitigation of visual impacts can occur in reality rather than just using careful positioning of the camera when producing photomontage visualisations.

The production of accurate visualisations is not merely a technical issue but also an ethical one. As Sheppard (2001) argues, preparation of visualisations needs to be governed by a code of ethics that covers broad principles and guidance on ethical conduct in producing and presenting visualisations. It is not just the matter of representing the size of wind turbines accurately by using appropriate focal lengths and visualisation techniques. Selecting locations from where photographs are taken for visualisations can also be regarded as a matter of ethics. Although this matter is not discussed in details here, field visits to viewpoints revealed that visualisations, especially for the onshore wind farm, were often taken from vantage points that resulted in the screening of one or many turbines, which could be considered dishonest. These observations are consistent with the findings of the University of Newcastle (2002, p. 59) report which also finds that the choice of viewpoints is often "less than ideal", and often shows a much reduced or even zero visual impact, even though the turbines are more prominent from a very short distance away from the viewpoint. Since photography can only produce relatively static visualisations from specific viewpoints, visualisations cannot capture the changing magnitude of visual impact that varies when moving through the landscape. This limitation can be overcome by using interactive and 3D visualisations techniques. However, despite the falling costs of these techniques in the past decade, the production of such visualisations is still more costly and time-consuming than the production of photomontages (Lovett et al. 2015).

One of the major limitations of this study is that it uses post-development photographs and not photomontages as alternative images to the panoramic photomontages. When taking a $75 \mathrm{~mm}$ full frame photograph of a wind farm post-construction, the size of wind turbines in the photo is perceived about the same as in reality. However, when taking a photograph with the same specification pre-development, the proposed wind turbines are not present in the photograph. The accuracy of visualisations therefore will also depend on the rendering techniques used and 
the decisions made in the preparation of the visualisations (Lewis, 2012). Another limitation of the study is that due to the use of a non-probability sampling technique, statistical generalisations of perceptions of accuracy of visualisations to larger populations are not possible. Nevertheless, Patton (2002) argues that using critical cases permits cautious logical generalisations, so it can be reasoned that if the $75 \mathrm{~mm}$ image format is perceived as the most accurate representation of the two case study wind farms, the same will be perceived for other wind farms at different locations. Finally, although some measures were taken to control the variables in the different scenes, differences in lighting, exposure or colouration (mainly between the panorama and full frame images) due to changes in the scenes over time and weather conditions were inevitable, which may have influenced responses on perceived accuracy and scale.

\section{Conclusions}

Assessing the accuracy of visualisations and evaluating the performance of predictive techniques used in VIA is important feedback to insure the credibility of visualisations. This study is unique in that it compared ex-ante visualisations with the reported direct observations of respondents post-construction rather than using ex-post photographs of finished sites, as previous studies have done before.

Results of the field visit and the public survey confirmed that panoramic photomontage visualisations underestimate the scale and visual impact of wind turbines and therefore should not be used as a technique for predicting the visual impact of proposed developments. On occasions when the aim is to show the wider landscape in which the proposed wind farm is set, it may be appropriate to use the panoramic image format. However, it should be made explicit that panoramic photomontages do not provide a realistic impression of the perceived scale of the wind turbines.

This research has shown that with the appropriate use of focal length it is possible to produce visualisations that depict the visual impact of wind farms more accurately. The $75 \mathrm{~mm}$ full frame image format is recommended for both onshore and offshore wind farm visualisations as this image format was perceived by most respondents to depict the scale and visual impact of the proposed development most accurately. In future research, assessing the accuracy of $75 \mathrm{~mm}$ panorama could be pursued to explore whether or not their perceived accuracy is even higher than that of the $75 \mathrm{~mm}$ full frame image. The results of this study also suggest that a longer focal length (between $75-90 \mathrm{~mm}$ ) may be more appropriate for offshore wind farm visualisations than the $75 \mathrm{~mm}$ focal length. Therefore, more research could be done on this, in addition to examining how VIA of other types of infrastructure may also benefit from a change in visualisation practice. 


\section{References}

Bates-Brkljac, N. (2009) Assessing perceived credibility of traditional and computer generated architectural representations. Design Studies, 30(4), pp. 415-437.

Baumert, K., Herzog, T. and Pershing, J. (2005) Navigating the numbers: greenhouse gas data and international climate change policy. WRI, Washington DC.

Bender, R. and Lange, S. (2001) Adjusting for multiple testing - when and how? Journal of clinical epidemiology, 54(4), pp. 343-349.

Bishop, I. D. and Miller, D. R. (2007) Visual assessment of off-shore wind turbines: the influence of distance, contrast, movement and social variables. Renew Energy, 32, pp. 814-31.

Bishop, I. D. and Rohrmann, B. (2003) Subjective responses to simulated and real environments: a comparison. Landscape and Urban Planning, 65, pp. 261-277.

Bisset, R. (1984) Post-development audits to investigate the accuracy of environmental impact predictions. Zeitschrift fur Umweltpolitik, 7, pp. 463-87.

Bradshaw, M. (2010) Global energy dilemmas: a geographical perspective. The Geographical Journal, 176(4), pp. 275-290. doi: 10.1111/j.1475-4959.2010.00375.x.

Churchward, C., Palmer, J. F., Nassauer, J. I. and Swanwick, C. A. (2013) Evaluation of Methodologies for Visual Impact Assessments. Transportation Research Board, Washington D. C.

Corry, R. C. (2011) A case study on visual impact assessment for wind energy development. Impact Assessment and Project Appraisal, 29(4), pp. 303-315.

Dai, K., Bergot, A., Liang, C., Xiang, W., Huang, Z. (2015) Environmental issues associated with wind energy - A review. Renewable Energy, 75, pp. 911-921.

Daniel, T. C. and Meitner, M. M. (2001) Representational validity of landscape visualizations: the effects of graphical realism on perceived scenic beauty of forest vistas. Journal of Environmental Psychology, 21, pp. 61-72.

DBEIS, 2018. Energy Trends March 2018. Department for Business, Energy and Industrial Strategy, UK Government. Published March 2018. Available at:

https://www.gov.uk/government/statistics/energy-trends-march-2018, last accessed 12/04/2018.

Downes, M. and Lange, E. (2015) What you see is not always what you get: A qualitative, comparative analysis of ex ante visualizations with ex post photography of landscape and architectural projects. Landscape and Urban Planning, 142, pp. 136-146.

EEA (2009) Europe's onshore and offshore wind energy potential. An assessment of environmental and economic constraints. Available at: https://www.energy.eu/publications/a07.pdf. Last accessed: $31 / 10 / 2018$.

Energy and Climate Change Committee (2016) 2020 Renewable heat and transport targets. Re-port by the House of Commons Energy and Climate Change Committee, September 2016, Re-port number HC173, Available at: https://publications.parliament.uk/pa/cm201617/cmselect/cmenergy/173/173.pdf. Last accessed 12/04/2018.

Gibson, J. J. (1950). The perception of the visual world. Cambridge, USA: The Riverside Press. 
Glaser, B. G. and Strauss, A. L. (1967) The discovery of grounded theory: Strategies for qualitative Research. Aldine, Chicago.

Hunter, P. D. and Livingstone, D. F. (2012) Effect of focal length on perceptions of scale and depth in landscape photographs: Implications for visualisation standards for wind energy development. The Highland Council, Inverness.

Hurtado, J.P., Fernandez, J., Parrondo, J. and Blanco, E. (2004) Spanish method of visual impact evaluation in wind farms. Renew Sustain Energy Rev, 8, pp. 483-491.

Kraft, R. N., Patterson, J. F. and Mitchell, N. B. (1986) Distance perception in photographic displays of natural settings. Perceptual and motor skills, 62(1), pp. 179-186.

Lange, E. (2001) The limits of realism: Perceptions of virtual landscapes. Landscape and Urban Planning, 54, 163-182.

Lewis, J. L. (2012) More art than science: the sources and effects of stylistic variation in visualization for planning and design. Environment and Planning B: Planning and Design, 39, pp. $551-565$.

Landscape Institute (2018) Photography and Photomontage in Landscape and Visual Impact Assessment. Draft Technical Guidance Note. Available at: https://www.landscapeinstitute.org/wpcontent/uploads/2018/06/draft-tin-2018-XX-photography-photomontage-lvia.pdf. Last accessed: $08 / 11 / 2018$.

LI and IEMA (Landscape Institute and Institute of Environmental Management and Assessment) (2013) Guidelines for Landscape and Visual Impact Assessment. 3rd edition, Routledge, London.

Lovett, A., Appleton, K., Warren-Kretzschmar, B. and Von Haaren, C. (2015) Using 3D visualization methods in landscape planning: An evaluation of options and practical issues. Landscape and Urban Planning, 142, pp. 85-94.

Macdonald, A. (2007) The visual issue. An investigation into the techniques and methodology used in windfarm computer visualisations. Available at: http://aawt.org.uk/thevisualissue.pdf. Last accessed: $11 / 09 / 2015$.

Macdonald, A. (2012) Windfarm Visualisation: Perspective or Perception? Whittles Publishing, Dunbeath Mill, UK.

MacLeay, I., Harris, K. and Annut, A. (2015) Digest of United Kingdom Energy Statistics 2015. Stationary Office, London.

Molnarova, K., Sklenicka, P., Stiborek, J., Svobodova, K., Salek, M. and Brabec, E. (2012) Visual preferences for wind turbines: Location, numbers and respondent characteristics. Applied Energy, 92, pp. 269-278.

Oh, K. (1994) A perceptual evaluation of computer-based landscape simulations. Landscape and Urban Planning, 28(2), pp. 201-216.

Patton, M. Q. (2002) Qualitative research and evaluation methods, (3rd ed.). Sage, Thousand Oaks, CA.

Pietsch, S. M. (2000) Computer visualisation in the design control of urban environments: a literature review. Environment and Planning B: Planning and Design, 27, pp. 521-536.

RenewableUK (2018) UK Wind Energy Database (UKWED). Available at: www.renewableuk.com/page/UKWEDSearch. Last accessed: 17/05/2018. 
Rodrigues, M., Montañés, C. and Fueyo, N. (2010) A method for the assessment of the visual impact caused by the large-scale deployment of renewable-energy facilities. Environmental Impact Assessment Review, 30, pp. 240-246.

Sharpe, D. (2015) Your Chi-Square Test is Statistically Significant: Now What? Practical Assessment, Research \& Evaluation, 20(8), pp. 1-10.

Sheppard, S. R. J. (1989) Visual Simulation: A User's Guide for Architect, Engineers, and Planners. Van Nostrand Reinhold, New York.

Sheppard, S. R. J. (2001) Guidance for crystal ball gazers: developing a code of ethics for landscape visualisation. Landscape and Urban Planning, 54, pp. 183-199.

Smardon R.C. and Karp, J.R. (1993) The Legal Landscape: Guidelines for Environmental and Aesthetic Quality Protection. Van Nostrand Reinhold, New York.

SNH (Scottish Natural Heritage) (2017) Visual Representation of Wind Farms. Guidance. Available at: https://www.nature.scot/sites/default/files/2017-

07/A2203860\%20-\%20Visual\%20representation \%20of\%20wind $\% 20$ farms $\% 20-\% 20$ Guidance $\% 20$ \%20Feb\%202017.pdf. Last accessed: 20/05/2018.

SPSS, version 22, SPSS Inc., Chicago.

Tomlinson, P. and Atkinson, S. F. (1987) Environmental audits: Proposed terminology. Environmental Monitoring and Assessment, 8, pp. 187-98.

Torres Sibille, A. C., Cloquell-Ballester, V., Cloquell-Ballester, V., and Darton, R. (2009) Development and validation of a multicriteria indicator for the assessment of objective aesthetic impact of wind farms. Renewable and Sustainable Energy Reviews, 13(1), pp. 40-66.

University of Newcastle (2002) Visual Assessment of Windfarms: Best Practice. Scottish Natural Heritage Commissioned Report, F01AA303A.

van Rensburg, T. M., Kelley, H. and Jeserich, N. (2015) What influences the probability of wind farm planning approval: Evidence from Ireland. Ecological Economics, 111, pp. 12-22.

Watzek, K. and Ellsworth, J. (1994) Perceived scale accuracy of computer visual simulations. Landscape Journal, 13(1), pp. 21-36.

Wergles, N. and Muhar, A. (2009) The role of computer visualization in the communication of urban design-A comparison of viewer responses to visualizations versus on-site visits. Landscape and Urban Planning, 91, pp. 171-182.

Wessels, J. A. (2013) Factors that influence the independence of EIA follow-up verifiers: A developing country perspective. Impact Assessment and Project Appraisal, 31(3), pp. 169-179.

Wood, G. (2000) Is what you see what you get? Post-development auditing of methods used for predicting the zone of visual influence in EIA. Environmental Impact Assessment Review, 20, pp. 537556.

World Energy Council (2015) World Energy Trilemma Priority actions on climate change and how to balance the trilemma. Available at: http://www.worldenergy.org/wp-content/uploads/2015/05/2015World-Energy-Trilemma-Priority-actions-on-climate-change-and-how-to-balance-the-trilemma.pdf. Last accessed: 14/09/2015. 